\title{
The Relationships Between Fall Risk, Depression, Executive Dysfunctions and Daily Life of Older Adults
}

\author{
Batya Engel Yeger ( $\nabla$ bengel@univ.haifa.ac.il ) \\ University of Haifa https://orcid.org/0000-0002-8975-9122 \\ Yael Zilbershlag \\ Ono Academic College
}

Research article

Keywords: older adults, fall risk, depression, cognition, executive functions, activities of daily living, quality of life

Posted Date: August 28th, 2020

DOI: https://doi.org/10.21203/rs.3.rs-55453/v1

License: (1) (1) This work is licensed under a Creative Commons Attribution 4.0 International License. Read Full License 


\section{Abstract}

Background: Falling is a major problem in older adults that may significantly reduce health and quality of life (QOL). Body dysfunctions that include depression, cognitive decline and executive dysfunctions may elevate fall risk and impair daily activities and QOL. Yet, most studies evaluate these body dysfunctions using laboratory measures in clinical settings. The present study aimed to: (1) compare these body dysfunctions between high/low risk fallers (2) examine the relationship between these body dysfunctions among the high risk fallers (3) explore the specific contribution of fall risk as a mediator between depression, executive dysfunctions and daily life.

Methods: Participants were 123 older adults who live in the community. Depression and cognitive status were measured by the GDS-15 and the MoCA. Fall risk was determined by a questionnaire supported by the Time Up and Go test (TUG). Executive functions (EF) were assessed by the BRIEF-A and the aEFPT medication management assessment. Daily activity performance was measured by the Barthel Index of ADL and the Instrumental ADL Scale. QOL was measured by the World Health Organization Quality of Life Brief Questionnaire.

Results: High fall risk was prevalent among $32 \%$ of the sample. High risk fallers had significantly lower cognitive level, higher depression, lower EF, lower daily activity performance and lower QOL. Among the high risk group, lower EF as measured in BRIEFA scales correlated with lower performance of daily activities and lower QOL. SEM model revealed that fall risk mediated between depression, executive dysfunctions and daily life.

Conclusions: Depression and executive dysfunctions are more prevalent in older adults with high fall risk and are significantly related to their daily activity performance and to their QOL. Community fall-prevention and rehabilitation programs should screen for fall risk and related body dysfunctions as expressed during daily activity performance and understand their impacts on people's QOL.

\section{Introduction}

Falling is a major problem in older adults. $30-40 \%$ of people over the age of 65 , who live in the community, fall at least once a year [1]. About half of them fall again in the following year and need long-term care [2]. The high health costs and the severe personal consequences - the injuries, immobilization, the reduced independence in daily activities, and death, turn falls to be a major concern for public health $[3,4]$. Based on studies found that some fallers show resilience and maintain or improve functioning [5], factors that underlie resiliency or vulnerability among fallers should be identified. Early screening of body dysfunctions and related restrictions in daily activities that predict falls may assist in elevating awareness to fall risk and improve prevention programs [6].

It is known that frail older adults are at greater fall risk. Other geriatric syndromes such as depression are more prevalent among people aged 65 and above with a history of falling. Depressive symptomatology has been even identified as a risk factor for falls, independent of antidepressant use [9]. Depression is also known to be related to executive dysfunctions in the elderly $[2,7,8]$.

The relation between falls, depression and executive dysfunctions is explained via changes that occur in biochemical mechanisms and in structures of the aged brain - the gray matter loss in somatosensory and motor areas, the prefrontal and the inferior parietal cortices [10], the loss of complexity of the neuronal connections [11] that impact motor, emotional and cognitive abilities $[9,12,13]$.

The high cognitive abilities named executive functions (EF) are responsible for the individual's controlled, goal-oriented behavior [14]. Thus, EF are essential for motor function, emotional regulation, for daily activity performance and for maintaining an active lifestyle $[15,16]$. Attention problems and uncontrolled goal-oriented behavior may significantly impair postural control and the maneuver around obstacles in the environment $[17,18]$. Brain imaging studies showed that the increased connectivity within the executive network mediated between the caudate head gray matter volume and fall risk via attentional changes among people with Parkinson's Disease (PD) [19]. Other studies found that EF deteriorate prior to, or at the same time as physical performance $[15,20]$ suggesting that EF are also associated with fall risk in the older adults with no PD. 
The frequent combination of reduced balance, impaired emotional status and executive dysfunctions may have far reaching impacts on older adults' daily life - they may decreased independence in Basic/Instrumental Activities of Daily Living (BADL/IADL) [21] and significantly reduce quality of life [3, 22-24]. Yet, a1 lack of information exists about the relationship between falls and depression in non-institutionalized older adults [2].

Several important points may be drawn from the literature: first, it is critical to elucidate key factors that contribute to loss of functioning as well as to resiliency. Second, being key factors in fall risk, the causative relationships between depression, EF, falls and daily function should be further explored. As for example: if depression is related to executive dysfunctions in the elderly, and both negatively impact daily activity performance, how does the fall risk affect this impact? Do older adults with depression, executive dysfunctions and higher fall risk differ in their daily activities' performance from those with only depression and executive dysfunction?

Moreover, when referring to daily activity performance - many studies use laboratory or neuro-psychological assessments. For example, EF are frequently evaluated by measures such as the Trail Making Test (TMT) [25], phonological fluency test (PF) [26]; Rey-Osterrieth Complex Figure test (ROCF) [27]. These measures refer to specific EF components and do not necessarily provide a thorough understanding of the impairments in real life. Information gathered from performance-based assessments with ecological validity in which task is the central part is missing. Using such tools may elaborate the knowledge about the individual's performance in real life [28] and express the precise manner in which balance-emotional-cognitive difficulties affect daily function. Moreover, by recognizing deterioration in emotional-cognitive/EF aspect during daily activity performance in routine lives, early intervention may be provided and minimize fall risk.

This approach is supported by the International Classification of Functioning Disability and Health (ICF) of the World Health Organization (WHO) [29]. According to this model, disability is no longer determined by body dysfunctions but by their interaction with the person's ability to perform daily activities. Moreover, performance of daily activities as well as quality of life are the main outcomes of intervention efficiency [30].

Since falls, depression and cognitive decline are usually recognized and detected in primary care, adequate and timely treatment is not always available, it is essential to elevate the awareness of older people, families and health care givers to emotionalcognitive early signs of falls and recognize them while older people perform daily life activities.

Based on the above, the aims of the present study were to: (1) examine fall risk prevalence among older adults living in the community. (2) compare depression, cognitive level/ executive functions, daily activity performance and QOL between high and low fall risk groups (3) Knowing that body functions such as cognitive level/ executive functions and depression may affect daily activity performance and QOL in the older age, this study aimed to explore what is the specific contribution of fall risk as a mediator between these body functions, daily activities and QOL.

\section{Methods}

\section{Participants}

This study included 123 old adults, aged 65-95 years, who lived in the community. Inclusion criteria: people who were not institutionalized in social or health centers, with no severe depression according to the Geriatric Depression Scale (GDS) [31]; people who scored 14 and above in the Montreal Cognitive Assessment (MoCA) [32] and were able to understand the study purpose, procedures and to sign the informed consent form. People with chronic illnesses such as high blood pressure, diabetes, osteoporosis, osteoarthritis, or urinary incontinence were included in the study. Most participants were using medications regularly ( $n=112,91.1 \%)$. Exclusion criteria: people with severe diseases such as Parkinson's Disease, Muscular Dystrophy, cancer, Dementia, severe and acute orthopedic limitations affecting function, significant visual impairments and those who were restraint to wheelchair or bed. Participants' socio-demographic information is included in table 1.

\section{Instruments}


Demographic and health status questionnaire, which also included the participants' current medication uptake.

\section{Depression and cognitive status were measured by:}

The Geriatric Depression scale, GDS-15 [31]- a self-report with 15 dichotomic items (yes/no questions) for screening depression in older adults. The total score ranges between 0-15 points. A higher score indicates more symptoms of depression. A score of $\geq 6$ indicates a need for a thorough medical/psychiatric assessment. A score of $\geq 11$ is considered a cutoff for indication of depression, and a higher score indicates higher depression severity.

The Montreal Cognitive assessment (MoCA) [32] - this short screening tool profile cognitive status. The areas of examination are visuo-spatial abilities, executive functions, attention, language, short term memory and orientation. Total score is achieved by summing the correct answers, up to a maximum of 30 points. The test is highly sensitive in identifying people with Mild Cognitive Impairment (MCl) (83\%-90\%) [32]. Based on an 8411 sample, Lu [33] noted that the appropriate cut of score for people without $\mathrm{MCl}$ or dementia and without formal education is $13 / 14$. Since our study included participants with and without formal education, the MoCA cutoff score in the current study was set at $\geq 14$.

\section{Assessment of fall risk was based on a questionnaire supported by a clinical examination:}

Based on the Israeli Ministry of Health (https://www.health.gov.il/PublicationsFiles/FallPreventionNationalProgram.pdf) [34], fall risk was determined according to two parameters:

(a) A questionnaire - that gathers information about the number of falls during the last year; information about fractions and significant injuries caused by falls; information about walking or stability difficulties.

(b) Time Up and Go test (TUG) [35]- this clinical examination measures mobility and lower extremity functions and is used as a screening tool for fall risk. The subject is requested to get up from a standard chair, without using upper extremity support, and walk three meters ahead in a regular pace. Then turn around and walk back to the chair and sit down. The subject can use a walking aid if needed. Rather that, no physical assistance is given throughout the test, but the examiner follows the participant in order to avoid any falling incidence. The test is carried out twice, but only the second round is scored. The score is the performance time in seconds measured by a stopwatch. Shorter performance time indicates better performance. A performance time longer than 13.5 seconds indicates fall [36].

In the present study, the high-risk group was defined when one of the three occurs: 1-the participant fell twice or more during the last year, 2-the participant had one fall during the last year with a significant injury, 3-the participant had one fall during the last year and a TUG score longer than 13.5 seconds.

\section{Assessment of EF by a self-report and a performance-based assessment:}

(a) The Behavior Rating Inventory of Executive Function-Adult Version (BRIEF-A) [37] which screens for possible executive dysfunction and indicates individuals' awareness of their own self-regulatory functioning. The BRIEF-A assesses everyday behaviors associated with specific domains of EF in adults that are summarized into two index scales: Behavioral Regulation Index (BRI) and Metacognition Index (MC) and a scale reflecting overall functioning (Global Executive Composite [GEC]). The BRI is composed of four scales: Inhibit, Shift, Emotional Control, and Self-Monitor. The MI is composed of five scales: Initiate, Working Memory, Plan/Organize, Task Monitor, and Organization of Materials. Behavior frequency is rated on a Likert Scale ranging from "rare" to "often". Raw scores are transferred into T scores $(M=50, S D=10)$. T scores at or above 65 reflect executive dysfunction.

(b) The medication management subtest of The Alternate Executive Function Performance Test (aEFPT) [16]- this an addition part of the valid performance-based EFPT assessment which measures EF while carrying out a daily task. The subjects' functional independence level and the amount of help required in these tasks are also recorded. The four original EFPT tasks are: cooking an oatmeal, telephone use, taking medication and paying a bill (Lysack, Neufeld, Mast, MacNeill, \& Lichtenberg, 2003). The aEFPT has four additional tasks - similar to the four original tasks but with a novel component to prevent a learning effect from the original form. In the medication management subtest - subjects are asked to sort medications into a 7-day pill sorter instead of taking a medication as requested in the original form [16]. The instruction is to find and sort medicines in a weekly pill 
sorter. For a successful performance, the subject has to ignore distractors (other bottles) and use prospective memory to follow the specific sorting instructions. In this study the medication management task was chosen since it is a daily common function among older adults, which does not require special facilities (like a stove top for cooking pasta, which is one of the subtests) and is relatively short in time.

The scoring refers to five executive functions: initiation, organizing, sequencing, safety and judgment and completion. Each component is scored on a scale of 0-5 points, according to the level of assistance required in order to complete the task: 5- Doing for participant, 4- physical assistance, 3-verbal direct instruction, 2- gestural guidance, 1- verbal guidance, 0 - independent. The score for the full task ranges between $0-25$, a higher score indicates more required assistance $[16,38]$.

\section{Daily life measures:}

(a) The Barthel Index of ADL [39]- which measures the performance of Basic Activities of Daily Living (BADL) in ten functional domains: eating, bathing, dressing, bowl and bladder control, personal hygiene, transfers, walking on straight surface and stair climbing. Item scores in 5-point intervals (0-15), depending on the level of assistance the participant requires. Total score range is 0-100, where higher score indicates better functional ability.

(b) Instrumental Activities of Daily Living Scale (IADL) [40]- this interview-based functional assessment consists of eight components: telephone use, shopping, food preparing, housekeeping, laundry, transportation use, responsibility for personal medication and money. Item scoring ranges between $0-3$ or $0-4$, according to the amount of assistance the participant requires. Total score ranges between $0-20$, where higher score indicates better functional ability.

(c) The World Health Organization Quality of Life Brief questionnaire (WHOQOL-BREF) [41] - this is an abbreviated 26 item version of the WHOQOL-100 which is the gold standards for measuring quality of life in four domains: physical, psychological, social relationships and environment. Scores in each domain range from 0 to 100 . Higher score represent higher quality of life.

\section{Procedure}

The research was authorized by the Ethics Committee of the Faculty of Social Welfare and Health Sciences, University of Haifa and Ono Academic College, Israel. Advertisements calling to participate in the study were published in neighborhoods in day care centers in the central Israel. Those who agreed to participate in the study, contacted the study conductor by phone. In this phone call they answered some questions to verity inclusion criteria. With those who answered the inclusion criteria, a meeting was set in their homes or in the day care center (after obtaining the approval of the management of day care centers). In the first meeting each participant signed an informed consent and continued to complete the evaluation battery - first the demographic and health status questionnaire, then the MoCA, The fall questionnaire, TUG test, and then the GDS, BRIEF-A, the aEFPT - medication management task, the ADL questionnaires and the WHOQOL-BREF. In case the participant got tired during the battery completion, the meeting was stopped, and a second meeting was set, to avoid exhaustion and complete the evaluations.

\section{Data Analysis}

All the analyses were performed using the Statistical Package for Social Sciences (SPSS) for Windows 25.0. T-tests, ANOVA and MANOVA examined whether significant differences existed between groups in all subscales / total scores of the dependent measures. Pearson correlation test examined the correlations between the dependent measures in the high fall risk group.

Structural Equation Modeling (SEM) was used to examine the relationships between age, education, depression, executive functions, performance of activities of daily living, health related quality of life and fall risk. The model examined the role of fall risk in mediating between all other parameters and daily life - in terms of ADL performance and QOL. For that, fall risk was calculated as a continues parameter and the examination was performed on the general sample. The following different fit indices were tested: the Goodness-of-Fit Statistic, Goodness-of-Fit Index (GFI), Root Mean Square Error of Approximation (RMSEA), Standardized Root Mean Square Residual (SRMR), Standardized RMR, and Comparative Fit Index (CFI). Chi-square was used for nested models comparison.

The level of significance was set at .05 . 


\section{Results}

In the present sample, high fall risk was prevalent among $32 \%$ of the sample.

Participants with high fall risk were slightly older than those with low fall risk, had fewer years of education, lower cognitive status, higher depression level, more executive dysfunctions - as manifested in performance based assessment (EFPT) and in the self-report -BRIEF-A (the largest difference was in working memory), more restrictions in basic/instrumental ADL and lower QOL (see table 2). Gender was not found to differ between both groups.

As presented in Table 3, better cognitive level, as assessed by MoCA correlated only with better performance in IADL. Depression level correlated with worse QOL, in all measured domains. Most of BRIEF-A scales correlated with BADL, IADL and all QOL domains, where lower executive functions correlated with lower performance of daily activities and lower QOL.

For examining the role of fall risk in mediating between body dysfunctions and daily life, fall risk was calculated as a continues parameter that included the TUG score (" 0 " = no risk or " 1 " = fall risk) plus the summary of the fall questionnaire scores. The range of the fall risk score was $0-10$ (mean $2.33 \pm 2.53$ ).

Then the correlations between the continues fall risk score and the other variables were examined. Higher fall risk score significantly correlated with elevated age $(r=.34, p<.0001)$, lower years of education $(r=-.35, p<.0001)$, higher depression $(r=.34$, $p<.0001)$, lower cognitive level $(r=-.31, p<.0001)$ and lower total QOL $(r=-.41, p<.0001)$.

Based on these significant correlations, the variables were entered to the SEM model.

The SEM model revealed good fit indices: $\chi^{2}(25)=38.275, \mathrm{p}=.04 ; \mathrm{CFI}=.97 ; \mathrm{NFI}=.93, \mathrm{RMSEA}=.06$.

There was a significant correlation between age and number of education years $(r=-.32, p<.0001)$ as well as between age and depression (GDS) $(r=.34, p<.0001)$.

Age was directly related to aEFPT Medication Management score $(\beta=.18, p=.03)$ and to lower performance in IADL $(\beta=-.25, p$ $<$.0001)- older adults had lower education, higher depression, reduced EF and restricted IADL.

Higher depression level (GDS score) correlated with lower number of education years $(r=-.39, p<.0001)$ and was directly related to lower Meta-Cognition and behavioral regulation (based on BRIEF-A) $(\beta=.55, p<.0001 ; \beta=.42, p<.0001$, respectively) and to lower performance in IADL $(\beta=-.23, p<.0001)$ - people with higher depression were less educated, had reduced EF and lower performance in IADL.

Lower Meta-Cognition (based on BRIEF-A) was directly related to higher risk fall and lower QOL $(\beta=.34, p=.005 ; \beta=-.31, p<.0001$, respectively).

Worse performance in aEFPT Medication Management score was directly related to lower number of education years $(\beta=-.37, p$ $<.0001)$ and to higher fall risk $(\beta=.32, p<.0001)$.

Fall risk was directly related to lower performance in BADL and IADL $(\beta=-.41, p<.0001 ; \beta=-.34, p<.0001)$ and to lower $Q O L$ ( $\beta=-$ $-.13, p=.05)$.

Fall risk did not mediate between BRIEF-A-BRI and BADL/IADL; BRIEF-A-BRI and QOL.

However, aEFPT Medication Management and meta-cognition in BRIEF-A were mediated to ADL and QOL by fall risk as follow: aEFPT and IADL (standardized indirect effect $=-.10)(95 \% \mathrm{Cl}:-.23-.04, \mathrm{p}<.001)$; aEFPT and BADL (standardized indirect effect=-.13) (95\% Cl: - .28-.04, p<.001); aEFPT and QOL (standardized indirect effect=-.04) (95\% Cl: - .11-.003, $p=.03)$; BRIEF-A$\mathrm{MI}$ and IADL (standardized indirect effect=-.11) (95\% Cl: $-.24-.03, \mathrm{p}=.003)$; BRIEF-A-MI and BADL (standardized indirect effect=-.14) (95\% Cl: - .29-.04, p = .004); BRIEF-A-MI and QOL (standardized indirect effect=-.04) (95\% Cl: $-.13-.002, \mathrm{p}=.04$ ); (see Fig. 1). The model explains $27 \%$ of the fall risk, $17 \%$ of the performance in BADL, $34 \%$ of the performance in IADL and $55 \%$ of total QOL. 
To summarize, in older adults fall risk has a significant role in mediating the association between depression, executive dysfunctions and daily life - as reflected by reduced performance of basic and instrumental ADL and in lower health related quality of life.

\section{Discussion}

This study examined the fall risk prevalence in older adults who live in the community. In line with the ICF model, this study examined the relationship between fall risk, other known geriatric body dysfunctions: depression; cognitive decline/executive dysfunctions, daily activity performance and QOL. The unique aspect of this study is that it combined the use of standard selfreports, clinical observation and performance-based assessments with ecological validity to understand the expressions of the body dysfunctions in daily situations.

Although this study referred to older adults who are relatively functional, about one third of them had high fall risk and significantly worse body dysfunctions that those with low fall risk. This was reflected in depression, lower cognitive status, lower executive functions, restricted ADL and lower QOL.

The findings of the present study support previous reports. The relationships between fall risk, depression and reduced executive dysfunctions, were explained by the less efficient cortical information processing and reduced attentional resources of the aged brain. The literature also supports the relationships found in the present study between these body dysfunctions and the personal-socio-demographic factors: depression was found to be more frequent in people with a medium-low socioeconomic status, with higher disability and comorbid conditions [22, 42-45]. Hence, fall-prevention programs in the elderly community should pay special attention to specific populations.

Yet, while a relatively large part of the studies about EF and falls have used traditional assessments in clinical settings and referred to particular domains of $\operatorname{EF}$ (e.g. inhibition, working memory) $[5,15]$, the present study used measures that reflected the executive dysfunctions in daily life- by using the BRIEF-A self-report and the performance-based aEFPT medication management test. The results showed that the greatest difference in EF between individuals with high fall risk and those with low fall risk was in BRIEF-A-working memory domain. Earlier reports mentioned that attention and memory are more affected by age and have greater impacts on posture control [22]. Moreover, EF were found to mediate the association between changes in memory and reduced performance in IADL [46].

These results are supported by the correlations presented in Table 3 - while cognitive level assessed by MoCA was not found to correlate with QOL, all BRIEF-A scales significantly correlated with almost all QOL domains, probably because of the ability of the BRIEF-A to reflect the dysfunctions as expressed in real life. These correlations also emphasize the far- reaching impacts of the combination of both executive dysfunction and fall risk in decreasing people's QOL. In order to better understand these relationships, the present study explored the specific contribution of fall risk to the relation between EF and daily activity performance, using the SEM model. Interestingly, not only that depression and reduced EF restrict the ability of older people to perform daily activities and experience good QOL, but the elevated fall risk augmented these restrictions significantly.

According to the SEM model, fall risk mediates between executive dysfunctions- and mainly meta-cognitive (MI) abilities, daily activity performance and QOL. First, MI components such as initiation, working memory, planning, monitoring and organization are more essential for motor planning, motor control and for overcoming obstacles in the environment. Second, an important aspect included in meta-cognition is awareness [47]. Awareness is critical for motor performance in the challenging environments, especially for older adults. Awareness is a key factor in cognitive rehabilitation. Awareness strategies are used to improve daily activity performance in populations with disabilities $[48,49]$. Hence, prevention and intervention programs for minimizing falls in older adults, should screen for EF problems and give special attention to the individual's meta-cognition, elevate the awareness to self-performance and to environmental context and cues (Burgess et al., 2006).

To achieve optimal intervention outcomes and in line with the ICF model, clinicians should gather information not only from isolated tasks in a lab setting, but from tasks that imitate daily life scenarios (Chaytor et al., 2006; Odhuba et al., 2005), with referral to the environmental context where the regulation of balance takes place [18]. With this information, clinicians may 
improve the choice of the best-adapted behavioral strategy $[16,28]$. For example, how to approach the activity in the certain environment, how to compensate the slow reaction time, or the physical difficulties [3], what environmental adaptations should be performed to enhance the adaptive responds to environmental demands at home or in the community [50].

\section{Conclusions}

Fall risk should be routinely screened among older people who live in the community and involvement in physical activity should be encouraged [51]. Moreover, health services should note that although older people's ability to function in daily activities is related to their emotional/cognitive/EF status affect, good balance and low falling tendency play a major role in this relationship. Hence, fall prevention and intervention programs should understand the impacts of these body dysfunctions on daily life [52], and look for impaired emotional-cognitive cues as expressed in daily activity performance of older people, in their natural environment. These cues may serve as red lights that predict the next fall and thus lead to early fall risk evaluation and intervention when needed. For that, intervention programs should be based on a multi-disciplinary approach, and apply models such as the ICF that were found to be relevant to fall rehabilitation [53]. Intervention should apply performance-based ecological assessments to map body dysfunctions that predict falls in real life context. By that intervention will be more directed to the person's specific needs, interests, resilience and vulnerability and promise better results in terms of enhanced daily function and better QOL.

This study has some limitations: it referred to a specific part of the population - older adults, who live in the community. The distribution of participants in each group - high/low fall risk was not equal. This study did not examine the role of concern about falling. Additional studies should refer to older adults who live in other settings such as nursing homes, examine the differences between men and women, use larger sample sizes to examine group differences. Cohort studies are also recommended in order to better understand aging impacts on falls, related body dysfunctions and expressions in people's daily function and life experience.

\section{Abbreviations}

Quality of life (QOL)

Executive functions (EF)

Basic/Instrumental Activities of Daily Living (BADL/IADL)

International Classification of Functioning Disability and Health (ICF)

World Health Organization (WHO)

Geriatric Depression Scale (GDS)

The Montreal Cognitive Assessment (MoCA)

Time Up and Go test (TUG)

The Behavior Rating Inventory of Executive Function-Adult Version (BRIEF-A)

Behavioral Regulation Index (BRI)

Metacognition Index (MC)

Global Executive Composite (GEC)

The Alternate Executive Function Performance Test (aEFPT)

Structural Equation Modeling (SEM)

Page 8/15 


\section{Declarations}

- Ethics Approval and Consent to Participate: the study was performed based on the ethics approval of the Ethics Committee of the Faculty of Social Welfare and Health Sciences, University of Haifa (number 007/18) and Ono Academic College, Israel, and after participants singed the written consent to participate in this study.

- Consent for publication - Not Applicable.

- Availability of Data and Materials - The datasets used and/or analyzed during the current study available from the corresponding author on reasonable request.

- Competing interests - The authors declare no competing interests.

- Funding - No funding was obtained for this study.

- Authors' contributions: Both authors composed the study, interpreted the data and wrote the manuscript.

- Acknowledgements - we acknowledge all participants for their contribution to the study.

\section{References}

1. Swift CG , Iliffe S. Assessment and Prevention of Falls in Older People-Concise Guidance. Clin Med. 2014; 14(6):658-62.

2. Pellicer-García B, Antón-Solanas I, Moreno-González S, Castro-Sánchez E, Juárez-Vela R. Prevalence of Depression and Associated Factors in Non-institutionalized Older Adults With a Previous History of Falling. Arch Psychiatr Nurs. 2017; 31(5):493-98.

3. Barban F, Annicchiarico R, Melideo M, Federici A, Lombardi MG, Giuli S, Ricci C, et al. Reducing Fall Risk With Combined Motor and Cognitive Training in Elderly Fallers. Brain Sci. 2017;7(2):19.

4. de Oliveira Cruz A, Maria Mota Santana S, Marinho Costa C, Vieira Gomes da Costa L, Dominguez Ferraz D. Prevalence of Falls in Frail Elderly Users of Ambulatory Assistive Devices: A Comparative Study. Disabil Rehabil Assist Technol. 2019, in press.

5. Best JR, Nagamatsu LS, Liu-Ambrose T. Improvements to executive function during exercise training predict maintenance of physical activity over the following year. Front Hum Neurosci. 2014; 8:353.

6. Saftari N, Kwon OS. Ageing Vision and Falls: A Review. J Physiol Anthropol. 2018; 37 (1), 11.

7. Promoting safe walking among older people: the effects of a physical and cognitive training intervention vs. physical training alone on mobility and falls among older community-dwelling men and women (the PASSWORD study): design and methods of a randomized controlled trial. Sipilä S, Tirkkonen A, Hänninen T, Laukkanen P, Alen M, Fielding RA, Kivipelto M, Kokko K, Kulmala J, Rantanen T, Sihvonen SE, Sillanpää E, Stigsdotter-Neely A, Törmäkangas T.BMC Geriatr. 2018;18(1):215.

8. Iaboni A, Flint AJ. The Complex Interplay of Depression and Falls in Older Adults: A Clinical Review. Am J Geriatr Psychiatry. 2013;21(5):484-92.

9. Kvelde T et al. Depressive Symptoms Increase Fall Risk in Older People, Independent of Antidepressant Use, and Reduced Executive and Physical Functioning. Arch Gerontol Geriatr. 2015;60(1):190-5.

10. McGinnis SM, Brickhouse M, Pascual B, Dickserson BC. Age related changes in the thickness of cortical zones in humans. Brain Topogr 2011; 24: 279-91.

11. Acker JD. Aging, sexual dimorphism, and hemispheric asymmetry of the cerebral cortex: Replicability of regional differences in volume. Neurobiol Aging 2004; 25: 377-96.

12. Biderman, A., Cwikel, J., Fried, A. V., \& Galinsky, D. (2002). Depression and falls among community dwelling elderly people: A search for common risk factors. Journal of Epidemiology and Community Health, 56, 631-636.

13. Gassmann, K. G., Rupprecht, R., \& Freiberger, E. (2009). Predictors for occasional and recurrent falls in community-dwelling older adults. Zeitschrift fu"r Gerontologie und Geriatrie, 42, 3-10.

14. Luiten PG, Nyakas C, Eisel U, Van der Zee E. Aging of the brain. In: Pfaff DW, Volkow ND. Neuroscience in the 21st Century. Springer-Verlag: New York 2013; pp. 2239-72. 
15. Caetano MJD et al. Executive Functioning, Concern About Falling and Quadriceps Strength Mediate the Relationship Between Impaired Gait Adaptability and Fall Risk in Older People. Gait Posture. 2018;59:188-192.

16. Hahn B, Baum C, Moore J, Ehrlich-Jones L, Spoeri S, Doherty M, Wolf TJ. Development of Additional Tasks for the Executive Function Performance Test. Am J Occup Ther. 2014;68(6):e241-6.

17. Di Fabio RP, Kurszewski WM, Jorgenson EE, Kunz RC. Footlift Asymmetry During Obstacle Avoidance in High-Risk Elderly. J Am Geriatr Soc. 2004 Dec;52(12):2088-93.

18. Bernard DL, Lacour M. The Fall in Older Adults: Physical and Cognitive Problems. Curr Aging Sci. 2017;10(3):185-200.

19. Rosenberg-Katz K, Herman T, Jacob Y, Mirelman A, Giladi N, Hendler T, Hausdorff JM. Fall Risk Is Associated With Amplified Functional Connectivity of the Central Executive Network in Patients With Parkinson's Disease. J Neurol. 2015 Nov;262(11):2448-56.

20. Atkinson HH, Rapp SR, Williamson JD, et al. The relationship between cognitive function and physical performance in older women: results from the women's health initiative memory study. J Gerontol A Biol Sci Med Sci. 2010; 65:300-306.

21. Fitzgerald DT , Hadjistavropoulos T, Williams J, Lix L, Zahir S, Alfano D, Scudds R. The Impact of Fall Risk Assessment on Nurse Fears, Patient Falls, and Functional Ability in Long-Term Care. Disabil Rehabil. 2016; 38 (11), 1041-52.

22. Laurence BD, Michel L. The Fall in Older Adults: Physical and Cognitive Problems. Curr Aging Sci. 2017;10(3):185-200.

23. Cohen HS. Use of the Vestibular Disorders Activities of Daily Living Scale to Describe Functional Limitations in Patients With Vestibular Disorders. J Vestib Res. 2014;24(1):33-8.

24. Christoforou A, van der Linden ML, Koufaki P. Short-term Effectiveness of a Community-Implemented Falls Prevention Referral Service. Disabil Rehabil. 2018; 40 (20), 2466-74.

25. Reitan RM. The relation of the trail making test to organic brain damage. J Consult Psychol. 1955; 19: 393-4.

26. Borkowisky JG, Benton, AL, Spreen O. Word fluency and brain damage. Neuropsychologia. 1967; 5:135-40.

27. Rey A. Memorisation D'une Serie de 15 Mots en 5 Repetitions; L'examen Clinique en Psycologie; Presses Universitaires de France: Paris, France, 1958.

28. Josman N, Elbaz Schenirderman A, Klinger E, Shevil E. Using virtual reality to evaluate executive functioning among persons with schizophrenia: A validity study. Schizophrenia Research. 2009;115(2-3):270-7.

29. World Health Organization. International classification of functioning, disability and health. Geneva: World Health Organization. 2001.

30. Engel-Yeger B. The Involvement of Altered Sensory Modulation in Neurological Conditions and Its Relevance to NeuroRehabilitation: A Narrative Literature Review. Disabil Rehabil. 2019; 12:1-10.

31. Yesavage JA, Brink TL, Rose TL, Lum O, Huang V, Adey M, Leirer VO. Development and validation of a geriatric depression screening scale: a preliminary report. Journal of psychiatric research. 1983; 17(1):37-49.

32. Nasreddine Z, Phillips N, Bédirian V, Charbonneau S, Whitehead V, Collin I, Chertkow H. The Montreal Cognitive Assessment, MoCA: a brief screening tool for mild cognitive impairment. Journal of the American geriatrics society. 2005; 53: 695-9.

33. Lu J, Li D, Li F, Zhou A, Wang F, Zuo X. et al. Montreal cognitive assessment in detecting cognitive impairment in Chinese elderly individuals: a population-based study. Journal of geriatric psychiatry and neurology, 2011; 24(4):184-190.

34. https://www.health.gov.il/PublicationsFiles/FallPreventionNationalProgram.pdf. Retrieved November 2017.

35. Podsiadlo D, Richardson S. The Timed "Up \& Go": a test of basic functional mobility for frail elderly persons. Journal of American Geriatrics Society. 1991; 39 (2): 142-8.

36. Herman T, Giladi N, Hausdorff JM. Properties of the 'timed up and go' test: more than meets the eye. Gerontology. 2011; 57(3):203-10.

37. Ciszewski S, Francis K, Mendella P, Bissada H, Tasca GA. Validity and reliability of the Behavior Rating Inventory of Executive Function Adult Version in a clinical sample with eating disorders. Eating behaviors. 2014; 15(2): 175-81.

38. Baum CM, Connor LT, Morrison T, Hahn M, Dromerick AW, Edwards DF. Reliability, validity, and clinical utility of the Executive Function Performance Test: A measure of executive function in a sample of people with stroke. American Journal of Occupational Therapy. 2008; 62: 446-455. 
39. Mahoney FI. Barthel DW. Functional evaluation: The Barthel Index. Maryland State Medical Journal. 1965; 14: 61-65.

40. Lawton MP, Brody EM. Assessment of older people: Self- maintaining and instrumental activities of daily living. Gerontologist. 1969; 9: 179-186.

41. Whoqol Group. Development of the World Health Organization WHOQOL-BREF quality of life assessment. Psychological medicine. 1998; 28(3):551-8.

42. Effect of cognitive and executive functions on perception of quality of life of cognitively normal elderly people dwelling in residential aged care facilities in Sri Lanka.

Gamage MWK, Hewage C, Pathirana KD.BMC Geriatr. 2018;18(1):256.

43. Beauchet O, Allali G, Annweiler C, Berrut G, Maarouf N, Herrmann FR., et al. Does change in gait while counting backward predict the occurrence of a first fall in older adults. Gerontology. 2008;54: 217-223.

44. Elderkin-Thompson V, Kumar A, Bilker WB, Dunkin JJ, Mintz J, Moberg PJ, Mesholam RI, Gur RE. Neuropsychological Deficits Among Patients With Late-Onset Minor and Major Depression. Arch Clin Neuropsychol. 2003;18(5):529-49.

45. Montero-Odasso M, Speechley M. Falls in Cognitively Impaired Older Adults: Implications for Risk Assessment And Prevention. J Am Geriatr Soc. 2018;66(2):367-75.

46. Royall DR, Palmer R, Chiodo LK, Polk MJ. Declining executive control in normal aging predicts change in functional status: the Freedom House Study. J Am Geriatr Soc. 2004; 52:346-352.

47. Toglia J, Kirk U. Understanding awareness deficits following brain injury. NeuroRehabilitation. 2000;15(1):57-70.

48. Toglia J, Johnston MV, Goverover Y, Dain B. A Multicontext Approach to Promoting Transfer of Strategy Use and Self Regulation After Brain Injury: An Exploratory Study. Brain Inj. 2010;24(4):664-77.

49. Engel-Yeger B, Durr DH, Josman N. Comparison of Memory and Meta-Memory Abilities of Children With Cochlear Implant and Normal Hearing Peers. Disabil Rehabil. 2011;33(9):770-7.

50. Mirelman A, Bonato P, Camicioli R, Ellis TD, Giladi N, Hamilton JL, Hass CJ, Hausdorff JM, Pelosin E, Almeida QJ. Gait Impairments in Parkinson's Disease. Lancet Neurol. 2019;18(7):697-708.

51. Ribeiro KM, Freitas RV, Ferreira LM, Deshpande N, Guerra RO. Effects of balance Vestibular Rehabilitation Therapy in elderly with Benign Paroxysmal Positional Vertigo: a randomized controlled trial.Disabil Rehabil. 2017;39(12):1198-1206.

52. Cohen HS, Kimball KT. Increased independence and decreased vertigo after vestibular rehabilitation. Otolaryngol Head Neck Surg. 2003;128(1):60-70.

53. Saverino A, Moriarty A, Rantell K, Waller D, Ayres R, Playford D. A Qualitative Description of Falls in a Neuro-Rehabilitation Unit: The Use of a Standardised Fall Report Including the International Classification of Functioning (ICF) to Describe Activities and Environmental Factors. Disabil Rehabil. 2015;37(4):355-62.

\section{Tables}

Table 1.

Comparing socio-demographic parameters, cognitive status, depression, executive functions, performance of activities of daily living and quality of life between groups

\begin{tabular}{|lllll|}
\hline & Total sample & Low fall risk $(\mathrm{n}=84)$ & High fall risk $(\mathrm{n}=39)$ & $\mathrm{p}$ \\
\hline Age (years, mean \pm SD) & $78.63 \pm 7.57$ & $77.81 \pm 7.66$ & $80.74 \pm 6.99$ & 0.05 \\
\hline Gender - men (\%) & 41.5 & 70.6 & 29.4 & NS \\
\hline Widows (\%) & & 29.8 & 53.8 & 0.01 \\
\hline Living alone (\%) & 38.2 & 65.1 & 34.9 & 0.017 \\
\hline Years of education (mean \pm SD) & $14.73 \pm 2.71$ & $13.77 \pm 4.37$ & $10.74 \pm 4.43$ & 0.05 \\
\hline Moderate/ poor socio-economic status (\%) & 35 & 27.4 & 51.3 & 0.010 \\
\hline Frail (\%) & 38 & 12.7 & 50 & 0 \\
\hline
\end{tabular}


\# Qualitative variables: Chi-square test; Quantitative variables: T-test NS=not significant

Page 12/15 
Table 2.

Comparing depression, EF, ADL and QOL between high/low risk fallers

\begin{tabular}{|c|c|c|c|c|}
\hline & & $\begin{array}{l}\text { Low fall risk } \\
(n=84)\end{array}$ & $\begin{array}{l}\text { High fall risk } \\
(n=39)\end{array}$ & \\
\hline & & mean $\pm S D$ & mean $\pm S D$ & $\begin{array}{l}\text { Statistic Significance of } \\
\text { differencesbetween high/low risk fallers }\end{array}$ \\
\hline MoCA & & $23.29 \pm 3.74$ & $20.94 \pm 4.11$ & 0.003 \\
\hline $\begin{array}{l}\text { Depression (GDS) } \\
(\text { mean } \pm S D)\end{array}$ & & $2.76 \pm 2.78$ & $3.85 \pm 2.73$ & 0.05 \\
\hline $\begin{array}{l}\text { aEFPT Medication } \\
\text { Management }\end{array}$ & & $2.21 \pm 2.84$ & $4.22 \pm 4.63$ & 0.05 \\
\hline \multirow[t]{12}{*}{ BRIEF-A } & Inhibition & $49.25 \pm 9.21$ & $51.53 \pm 9.97$ & NS \\
\hline & Shift & $55.23 \pm 12.17$ & $60.05 \pm 15.55$ & NS \\
\hline & Emotional control & $54.62 \pm 13.35$ & $61.81 \pm 15.54$ & 0.01 \\
\hline & Self-monitor & $45.17 \pm 8.13$ & $49.14 \pm 11.21$ & 0.03 \\
\hline & Initiate & $51.23 \pm 10.11$ & $55.54 \pm 16.26$ & NS \\
\hline & Working memory & $55.98 \pm 12.83$ & $64.53 \pm 16.72$ & 0.003 \\
\hline & Plan/organize & $54.44 \pm 11.83$ & $57.61 \pm 15.19$ & NS \\
\hline & Task monitor & $51.81 \pm 9.85$ & $55.28 \pm 13.24$ & NS \\
\hline & $\begin{array}{l}\text { Organization of } \\
\text { materials }\end{array}$ & $50.68 \pm 12.97$ & $52.25 \pm 12.98$ & NS \\
\hline & BRI & $41.30 \pm 8.88$ & $45.51 \pm 10.95$ & 0.01 \\
\hline & $\mathrm{Ml}$ & $56.97 \pm 12.16$ & $61.60 \pm 15.97$ & 0.05 \\
\hline & GEC & $97.82 \pm 19.32$ & $107.11 \pm 25.83$ & 0.02 \\
\hline BADL & & $97.82 \pm 6.14$ & $92.01 \pm 10.65$ & 0.004 \\
\hline IADL & & $19.62 \pm 4.17$ & $16.23 \pm 5.81$ & 0.003 \\
\hline \multirow[t]{5}{*}{ QOL } & Physical & $69.29 \pm 18.83$ & $54.79 \pm 20.93$ & 0 \\
\hline & Psychological & $75.46 \pm 16.52$ & $68.43 \pm 18.58$ & 0.04 \\
\hline & Social & $76.24 \pm 18.25$ & $71.91 \pm 20.52$ & NS \\
\hline & Environmental & $76.52 \pm 14.68$ & $69.54 \pm 15.68$ & 0.02 \\
\hline & Total & $74.37 \pm 14.17$ & $66.16 \pm 16.27$ & 0.006 \\
\hline
\end{tabular}

\# Quantitative variables: T- test, ANOVA, MANOVA; NS=not significant BRIEF-A-MI components are marked in Italic 
Table 3.

The significant correlations between cognitive level, depression, executive functions and QOL in the high fall risk group

\begin{tabular}{|c|c|c|c|c|c|c|c|c|}
\hline & & BADL & IADL & $\begin{array}{l}\text { Physical } \\
\text { QOL }\end{array}$ & $\begin{array}{l}\text { Psychological } \\
\text { QOL }\end{array}$ & $\begin{array}{l}\text { Social } \\
\text { QOL }\end{array}$ & $\begin{array}{l}\text { Environmental } \\
\text { QOL }\end{array}$ & $\begin{array}{l}\text { Total } \\
\text { QOL }\end{array}$ \\
\hline MoCA & & & $.513^{\star \star}$ & & & & & \\
\hline $\begin{array}{l}\text { Depression } \\
\text { (GDS) }\end{array}$ & & & & $-.423^{\star}$ * & $-.633^{\star \star \star} \star$ & $\star^{-.537 \star \star}$ & $-.517 * \star *$ & ${ }_{\star}^{-.617 \star \star}$ \\
\hline \multirow[t]{12}{*}{ BRIEF-A } & Inhibition & & & & & & & \\
\hline & Shift & & & $-.555^{\star \star \star \star}$ & $-.647 * \star \star *$ & & $-.474^{\star \star}$ & ${ }_{\star}^{-.565^{\star \star}}$ \\
\hline & $\begin{array}{l}\text { Emotional } \\
\text { control }\end{array}$ & & & $-.479 \star \star$ & $-.524 * \star *$ & & $-.450 \star \star$ & $-.515^{\star \star}$ \\
\hline & Self-monitor & $-.440 \star \star$ & $-.384^{\star}$ & $-.478^{\star \star}$ & $-.423^{\star}$ & & $-.384^{\star}$ & $-.408^{\star}$ \\
\hline & Initiate & 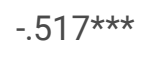 & $-.521^{\star \star \star}$ & 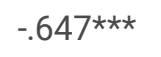 & $-.558 * \star \star$ & & $-.519 \star \star \star$ & $-.592 \star \star \star$ \\
\hline & $\begin{array}{l}\text { Working } \\
\text { memory }\end{array}$ & & & $-.582^{\star \star \star}$ & 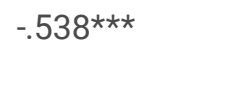 & $-.371^{\star}$ & $-.491^{\star \star}$ & $-.583^{\star \star *}$ \\
\hline & Plan/organize & $-.493^{\star \star}$ & $-.506^{\star \star}$ & 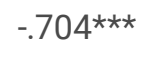 & 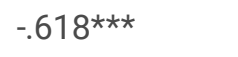 & $-.390 \star$ & 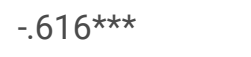 & $-.683^{\star \star \star}$ \\
\hline & Task monitor & & $-.341 *$ & $-.577 \star \star \star$ & $-.490 \star \star$ & & $-.588 \star \star \star$ & $-.563^{\star \star \star}$ \\
\hline & $\begin{array}{l}\text { Organization } \\
\text { of materials }\end{array}$ & $-.374^{\star}$ & & $-.384^{\star}$ & $-.449 \star \star$ & & $-.422^{\star \star}$ & $-.419 \star \star$ \\
\hline & BRI & $-.353^{\star}$ & $-.346^{\star}$ & $-.530 \star \star \star$ & $-.558 \star \star \star$ & & $-.465^{\star \star}$ & $-.520 \star \star \star$ \\
\hline & $\mathrm{Ml}$ & $-.435^{\star \star}$ & $-.438 * \star$ & $-.663^{\star \star \star}$ & 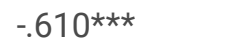 & $-.349 *$ & 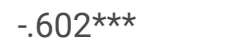 & $-.651 * \star \star$ \\
\hline & GEC & $-.419 \star$ & $-.418^{\star}$ & $-.635^{\star \star \star}$ & $-.614^{\star \star \star}$ & & 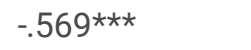 & $-.623 * \star \star$ \\
\hline
\end{tabular}

${ }^{*} \mathrm{p}<.05$

$\star * \mathrm{p}<.01$

$\star * \mathrm{p}<.001$

\section{Figures}




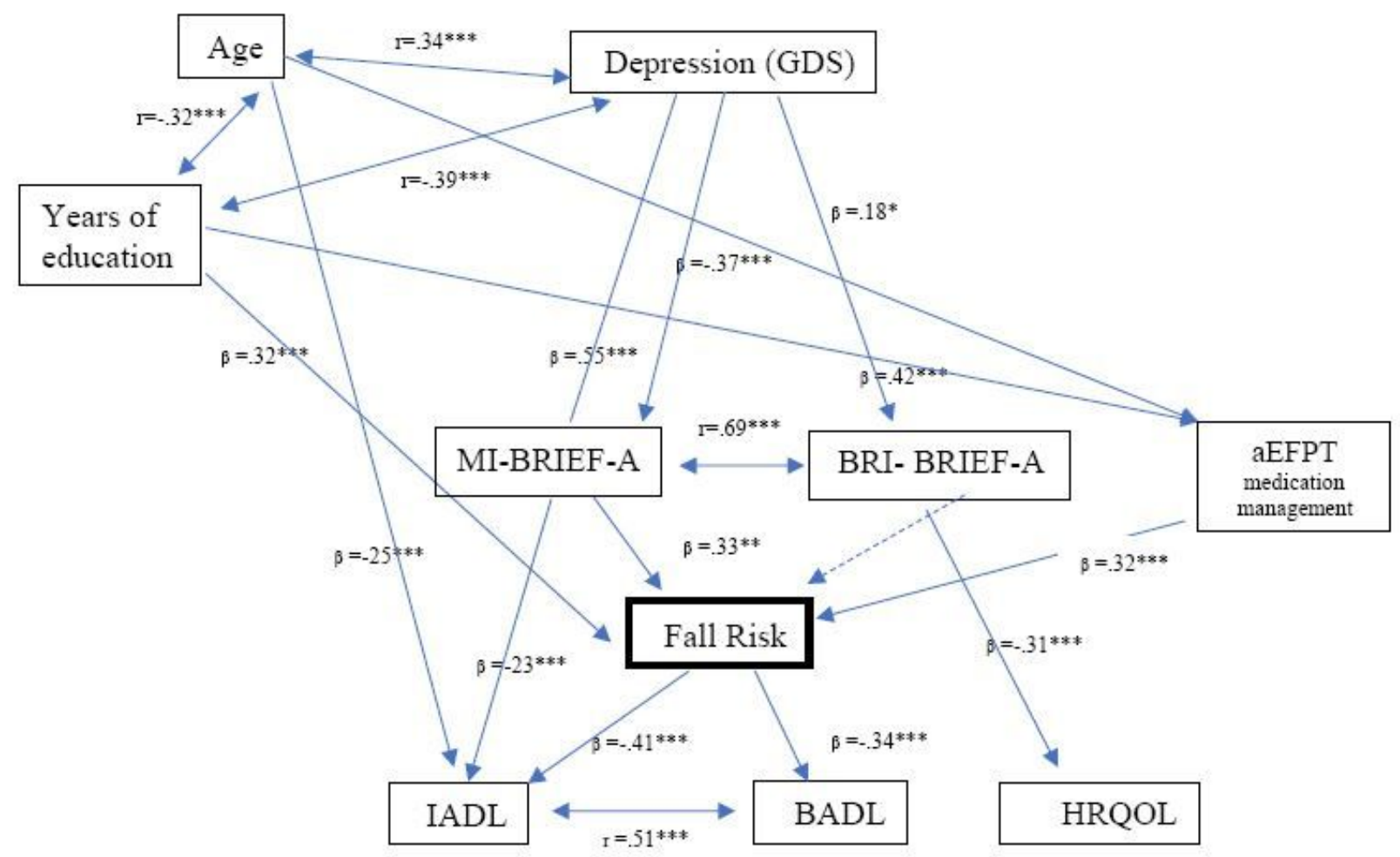

\section{Figure 1}

Structural equation modeling - fall risk medicate the association between executive dysfunctions and daily life ${ }^{*} \mathrm{p} \leq .05 ;{ }^{* *} \mathrm{p} \leq .01$; ${ }^{*} * \star \mathrm{p} \leq .001 \mathrm{GDS}=$ The Geriatric Depression Scale; BRIEF-A= The Behavior Rating Inventory of Executive Function-Adult Version ; aEFPT = The Alternative Executive Function Performance Test; $\mathrm{Ml}=$ meta cognition; BRI=behavioral regulation index; $\mathrm{BADL}=\mathrm{Basic}$ activities of daily living; IADL = instrumental activities of daily living; HRQOL = Health related quality of life; Dashed line = nonsignificant effect 